\title{
Factors leading to cesarean section delivery at Felegehiwot referral hospital, Northwest Ethiopia: a retrospective record review
}

\author{
Fantu Eyowas Abebe ${ }^{1 *}$, Abebaw Worku Gebeyehu², Ashebir Negasi Kidane ${ }^{1}$ and Gizached Aynalem Eyassu ${ }^{3}$
}

\begin{abstract}
Background: Cesarean section is the commonest obstetric operative procedure worldwide. When used appropriately cesarean sections can improve infant and/or maternal outcomes. However, when used inappropriately the potential harm may exceed the potential benefit of cesarean section. Appreciating the limited information in this area the current study assessed the rate and factors associated with cesarean section in Felegehiwot referral hospital, Bahir Dar, northwest Ethiopia.

Method: The study was a retrospective analysis of eligible patient records that included 2967 pregnant women who had underwent either cesarean or vaginal delivery from July 1, 2012 to June 31, 2013. The data were double entered to EPI-INFO 3.5.2 and analyzed with SPSS. Binary logistic regression model was fitted to identify independent factors associated with cesarean section.

Result: The proportion of women who underwent cesarean section in this study was $25.4 \%$. Obstructed labor (30.7\%), fetal distress (15.9\%) and abnormal presentation (13.4\%) were the major obstetric indications for cesarean section. The odd of undergoing cesarean section was higher among mothers in rural residence (AOR $=1.63,95 \%$ Cl: $1.21,2.20$ ), mothers reported to have pregnancy risk factors ( $A O R=2.31,95 \% \mathrm{Cl}: 1.74,3.07$ ) and lower among mothers in age category of $15-19$ (AOR $=0.63,95 \% \mathrm{Cl}: 0.43,0.93)$.

Conclusion: Obstetric factors occurring around birth, including obstructed labor and fetal distress were the main reasons leading to Cesarean Section rather than background characteristics assumed to be a risk. The results imply that there is a need for timely and accurate screening of women during obstetric care and, decision to perform cesarean section should be based on clear, compelling and well-supported justifications.
\end{abstract}

Keywords: Cesarean section, Retrospective record review, Ethiopia

\section{Background}

Cesarean section is the commonest obstetric operative procedure worldwide $[1,2]$. When used appropriately Csections can improve infant and/or maternal outcomes. However, when used inappropriately the potential harm may exceed the potential benefit of C-section. C-sections cost more than vaginal births and can result in increased risk to mother and baby $[2,3]$. There is a growing concern that Cesarean rates have been rising for all women in the world regardless of medical condition, age, race, or

\footnotetext{
* Correspondence: fantuabebe@gmail.com

${ }^{1}$ Strengthening Human Resource for Health Project, iNGO, P.O. Box, 1566

Bahir Dar, Ethiopia

Full list of author information is available at the end of the article
}

gestational age. International concern over such increases have prompted the World Health Organization to suggest that CS rates should not exceed $15 \%$ [4], with some evidence indicating caesarean section rates above $15 \%$ are not associated with additional reduction in maternal and neonatal mortality and morbidity $[5,6]$.

Modern obstetrics practice for medical, social, economic and legal reasons have witnessed an increase in the primary cesarean section rates everywhere [7-16]. While the Cesarean Section rate ranges between 12 and $86 \%$ across studies done in developed countries $[6,7,10,17]$ and the rate in developing countries vary between 2 and $39 \%$ $[2,4,6,12,18,19]$. 
Caesarean section delivery is increasing in Ethiopia [20], indicative of access to obstetric care service in the country. In the urbanized region of the country, the rate ranges from 8 to $37 \%[20,21]$. The increment in caesarean section delivery rate in major urban cities is a cause of concern as it surpasses the WHO threshold of $15 \%$. However, according to the Ethiopian demographic and health survey 2011 report, only $2 \%$ of the women had undergone caesarean section [22].

Many factors have been claimed to attribute for increased cesarean section rate across the world. While some literatures $[3,4,6,14]$ reported Premature Rupture of the amniotic fluid Membrane (PROM), Cephalic Pelvic Disproportion (CPD), fetal distress, multiple pregnancy and breech presentation as factors associated with increased rate of caesarean section. Some others revealed that it is associated with place of health seeking (private with public) and maternal preferences [9, 20, 23, 24].

Few other studies also demonstrated the relationship between cesarean section and maternal age [9, 24, 25]. Even some other studies find out that, birth weight, parity, maternal height and history of antenatal care visit (ANC) to be factors associated with cesarean section $[10,17]$.

Ante Partum hemorrhage (APH), multiple pregnancy, cord prolapse, mothers HIV infection condition and having previous history of cesarean section were also found to be factors leading to increased cesarean section rate $[12,18,19]$. The improved safety of surgical and anesthetic skills in modern obstetrics and mothers positive attitudes towards CS among staff and patients could also be the other factors that contribute for increased rate of cesarean section.

It has been shown that a significant number of obstetricians would agree to perform an elective CS without an obstetrical indication upon maternal request $[9,24,26]$. Currently there is much debate as to whether this surgical procedure should be performed for women without clear clinically acceptable indications $[1,6,7]$. Even, in Ethiopia, perhaps in the region little information is available with regard to the magnitude and factors associated with rate of C-section in hospitals. Thus, this study intended to assess the magnitude and factors associated with cesarean section in Felegehiwot Referral Hospital, Amara region, Northwest Ethiopia.

\section{Methods}

\section{Study setting and design}

The study was a retrospective analysis of eligible and complete client records that included 2967 pregnant women who had undergone either cesarean or vaginal delivery from July 1, 2012 to June 31, 2013 in Felegehiwot Referral Hospital, Amhara region, Northwest Ethiopia.
This hospital is one of the five busiest referral hospitals in the region. It is proximal to serve about 5,000,000 people including pregnant women where majority of them are usually referred from neighboring zonal hospitals, health centers, health posts and private health facilities.

\section{Data collection and analysis}

Pre-tested questioner was used to collect mothers' information including age, parity, gestational age, antenatal care, stage of labor at admission, fetal condition at admission, reason for admission prior to intervention, onset of labor, spontaneous or induced, oxytocin infusions, instrumentation and reason for referral before admission to the hospital.

\section{Inclusion and exclusion criteria}

A total of 3460 women were registered for maternity care, including abortion care over the year. We identified and reviewed 3063 eligible maternal charts. Of which, 60 charts were incomplete and were excluded from the study. Furthermore, 36 charts of the women who had uterine rupture were also excluded and the final sample size became 2967.

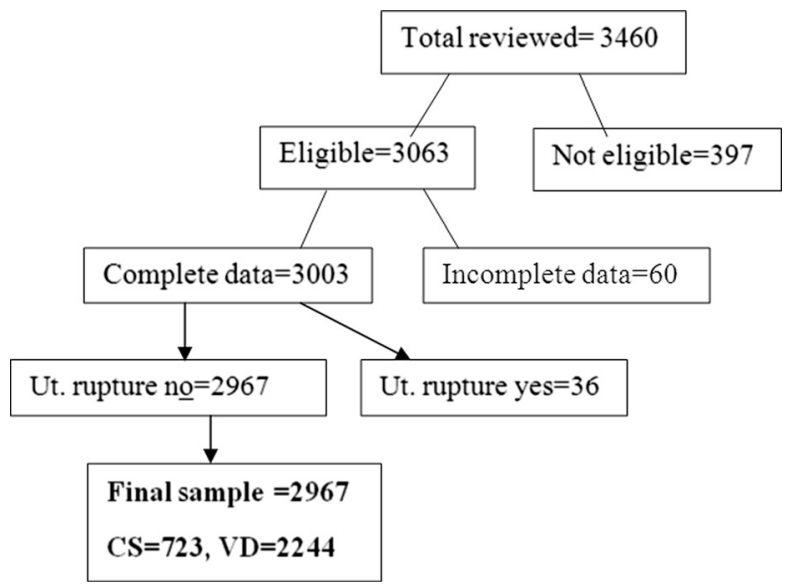

The completeness and consistency of the data was checked, cleaned and double entered to EPI-INFO software version 3.5.2 and analyzed by SPSS software version 16. Binary logistic regression model was applied to handle potential confounding variables and to identify independent factors associated with cesarean section. In order to avoid collinearity between different factors, two models were fitted independently. The first model considered more of background characteristics (more distal factors) whereas the second model focused on immediate causes of CS. Significance was taken at $P$ value of $<0.05$. Model fitness was checked using Hosmer and Lemeshow goodness of fit test. 


\section{Ethical consideration}

Ethical approval to conduct the study was obtained from Amhara Regional Health Bureau research ethics review committee. Communication with the hospital administration made through formal letter obtained from the regional health bureau. The data obtained from the hospital was kept confidential.

\section{Result}

Among the 2967 eligible mothers, 723 (25.3\%) had CS delivery. The majority $653(90.3 \%)$ of these women had emergency CS and referred cases were responsible for the higher (79\%) proportion of emergency CS in this study. Women who were referred from other facilities constitute close to $73 \%$ of the total study participants.

Eight nine mothers had previous CS delivery. Among these women, 30 (37.8\%) had attempted Vaginal Birth After CS (VBAC) and only 19 (63.3\%) of them had successful vaginal delivery.

Among the 271women who had induction, 32 (11.8 \%) of them ended up with CS delivery. During the last pregnancy, 2321(77.3 \%) of the mothers had ANC visits, of whom, 1465 (63.1 \%) of the women had four or more ANC visits.

Of the total 723 CS deliveries, 364 (50.3\%) were made by general anesthesia and the remaining were spinal anesthesia. Nine mothers were reportedly died during/following CS delivery and related to the use of general anesthesia. Respiratory failure was responsible for the majority $4(44.4 \%)$ of maternal deaths. Two women died due to hemorrhagic shock and 2 of them died due to disseminated intravascular coagulation and the remaining one was due to aspiration pneumonia. Forty-seven women (6.5\%) had unjustified CS for a dead fetus.

The detail analysis of vaginal delivery showed that there were $1855(82.7 \%)$ spontaneous vaginal deliveries, 349 (15.6\%) assisted vaginal/instrumental deliveries including the four assisted vaginal birth after CS, 25 (1.1\%) destructive deliveries and $15(0.66 \%)$ spontaneous vaginal births after previous CS.

In this study, 269 (9.06 \%) newborns were stillbirths. The still birth rate for CS (excluding 36 cases due to uterine rupture) and vaginal delivery was 6.5 and $9.9 \%$ respectively. On the other hand, ten of the 13 immediate newborn deaths were incriminated to CS delivery and the majority $(80 \%)$ of these immediate newborn deaths was related to the use of general anesthesia. However, the overall perinatal mortality rate in the reference hospital was $10.5 \%$ (8.4\% for CS and $11.1 \%$ for vaginal delivery).

True labor, leakage of liquor, preeclampsia, vaginal bleeding and postdate were the common causes of admission
Table 1 Reasons for admission of pregnant women in Felegehiwot referral hospital, Bahir Dar, Ethiopia 2013

\begin{tabular}{lll}
\hline Reasons for admission & \multicolumn{2}{l}{ Route of delivery } \\
\cline { 2 - 3 } & All forms of vaginal delivery & CS \\
\hline True signs of labor & $1746(77.8 \%)$ & $501(69.3 \%)$ \\
Leakage of liquor & $214(9.7 \%)$ & $58(8.0 \%)$ \\
Preeclampsia/eclampsia & $72(3.2 \%)$ & $44(6.1 \%)$ \\
Absent fetal movement & $62(2.8 \%)$ & $9(1.2 \%)$ \\
Post date & $53(2.4 \%)$ & $40(5.5 \%)$ \\
Vaginal bleeding & $52(2.3 \%)$ & $46(6.4 \%)$ \\
Bad obstetric history & $24(1.1 \%)$ & $17(2.4 \%)$ \\
Retained second twin & $18(0.8 \%)$ & $3(0.4 \%)$ \\
Previous CS & $0(0 \%)$ & $5(0.7 \%)$ \\
Total & $2244(100 \%)$ & $723(100 \%)$ \\
\hline
\end{tabular}

for both vaginal and CS delivery in this referral hospital (Table 1).

Quite a significant number of mothers have had preventable complications and most of the complications were happened during or following vaginal delivery (Table 2).

In this study, several reasons were identified as an indication for CS delivery. The most frequent indication was obstructed labor (30.7 \%) followed by fetal distress (15.9\%), abnormal presentation (13.4\%), previous CS scar (7.9) and failure to progress (6.8) (Fig. 1). Of the total 222 women who had CS due to obstructed labor, $190(85.6 \%)$ women had obstructed labor on arrival and 34 (14.4\%) women had obstructed labor that happened within the hospital.

Obstructed labor was the leading obstetric indicator for CS among both referral cases and direct admissions (Table 3). All of the institutional maternal deaths and seven of the immediate newborn deaths were from referral cases.

Table 2 Intrapartum and postpartum maternal complications observed among women enrolled for the study, Felegehiwot referral hospital, Bahir Dar, Ethiopia 2013

\begin{tabular}{llll}
\hline Complications & \multicolumn{2}{l}{ Route of delivery } & Total \\
\cline { 2 - 3 } & Vaginal delivery & CS delivery & \\
\hline 1st degree perineal tear & $74(36.6)$ & - & 74 \\
2nd degree perineal tear & $66(32.6)$ & - & 66 \\
Hemorrhage & $35(17.4)$ & $20(27.0)$ & 55 \\
Preeclampsia/Eclampsia & $17(8.5)$ & $14(18.9)$ & 31 \\
Wound infection & - & $23(31.1)$ & 23 \\
Sepsis & $8(3.9)$ & $8(10.8)$ & 16 \\
Maternal death & 0 & $9(12.2)$ & 9 \\
Vesico-vaginal fistula & $2(1.0)$ & - & 2 \\
Total & $202(100 \%)$ & $74(100 \%)$ & 276 \\
\hline
\end{tabular}


Percent Proportion of indications for CS

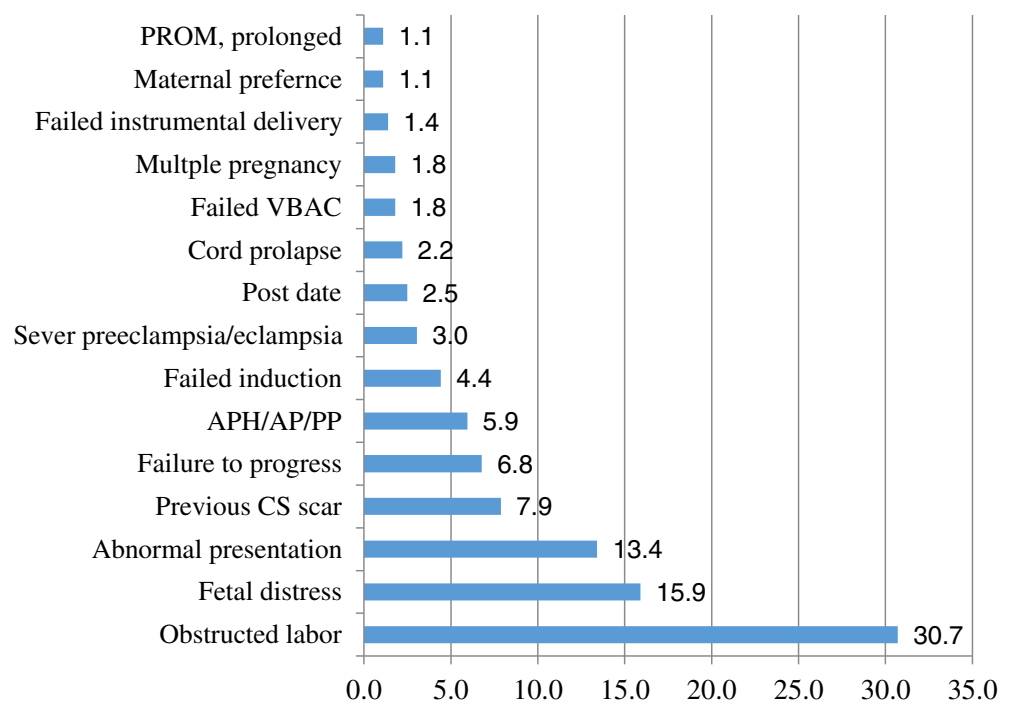

Fig. 1 Percent proportion of obstetric indications for CS delivery, FHRH, Amhara, Ethiopia, July 2014

\section{Differentials of cesarean section delivery}

After adjusting for other factors, residence (may be due to referral or selection bias), maternal age and presence of risk factor showed significant association with cesarean section. Likewise, the odds of undergoing cesarean section was 1.67 (AOR $=1.67,95 \% \mathrm{CI}: 1.39,199)$ and 2.31 (AOR $=2.31,95 \%$ CI: $1.74,3.07)$ times higher among women from rural and having history of risk factors, respectively.

Table 3 Comparisons of obstetrics indication of CS and mode of admission

\begin{tabular}{lll}
\hline Reasons for CS & \multicolumn{2}{l}{ Mode of admission } \\
\cline { 2 - 3 } & Referred cases & Direct admission \\
\hline Obstructed labor & $190(33.1)$ & $32(21.5)$ \\
Feta distress/NRFHP & $84(14.6)$ & $31(20.8)$ \\
Abnormal presentation & $80(13.9)$ & $17(11.4)$ \\
Previous CS scar & $40(7.0)$ & $17(11.4)$ \\
Failure to progress & $41(7.1)$ & $8(5.4)$ \\
APH & $34(5.9)$ & $9(6.0)$ \\
Failed induction & $21(3.7)$ & $11(7.4)$ \\
Sever preeclampsia/eclampsia & $18(3.1)$ & $4(2.7)$ \\
Post date & $15(2.6)$ & $3(2.0)$ \\
Cord Prolapse & $13(2.3)$ & $3(2.0)$ \\
Multiple gestation & $10(1.7)$ & $3(2.0)$ \\
Failed instrumental delivery & $10(1.7)$ & $0(0.0)$ \\
Failed VBAC & $7(1.2)$ & $6(4.0)$ \\
Maternal preference & $5(0.9)$ & $3(2.0)$ \\
Prolonged PROM & $6(1.0)$ & $2(1.3)$ \\
Total & $574(100)$ & $149(100)$ \\
\hline
\end{tabular}

Similarly women in the age category of 15-19 had $37 \%$ lower (AOR $=0.63,95 \%$ CI: $0.43,0.93$ ) probability of CS delivery compared to age category of $20-34$ years). Furthermore, the odds of experiencing cesarean section was $9.80(\mathrm{AOR}=9.80,95 \% \mathrm{CI}: 7.16,13.42)$ higher if the woman had abnormal presentations. Similarly a women having history of previous cesarean section and fetal weight of $4000 \mathrm{gm}$ and more were $3.93(\mathrm{AOR}=3.93,95 \%$ CI: $2.39,6.44)$ and $13.68(\mathrm{AOR}=13.68,95 \% \mathrm{CI}: 7.87$, 23.78) times more likely to give birth by cesarean section (Table 4).

\section{Discussion}

Cesarean Section is a life-saving procedure for both the mother and the baby. Delay in deciding for it may be detrimental for both. On the other hand, premature and wrong decision may increase the maternal and fetal morbidity and mortality. The purpose of this study was to determine the magnitude of CS delivery and to identify factors leading to CS in Felegehiwot referral hospital.

The proportion of women undergoing CS delivery in this study was $25.4 \%$. This finding is consistent with studies conducted in other parts of Ethiopia [20, 21]. This magnitude may be attributed to high number of referral cases. Therefore, the observed proportion cannot be used as reference data for the source population. However, the result is insightful for researchers and program personnel, for example, all maternal and the majority of immediate neonatal deaths were observed in relation to CS delivery. Presence of unforeseen complications, delay in making decisions or inadequate care might contribute to the observed result. Some previous 
Table 4 Bivariate and multivariate analysis of factors associated with cesarean section delivery at Felegehiwot referral hospital, Bahir Dar, Ethiopia, 2013

\begin{tabular}{|c|c|c|c|c|}
\hline \multirow[t]{2}{*}{ Variables } & \multicolumn{2}{|c|}{ Route of delivery } & \multirow[t]{2}{*}{ COR $(95 \% \mathrm{Cl})$} & \multirow[t]{2}{*}{ AOR $(95 \% \mathrm{Cl})$} \\
\hline & CS (\%) & All vaginal (\%) & & \\
\hline \multicolumn{5}{|l|}{ Model 1 (distal factors) } \\
\hline \multicolumn{5}{|l|}{ Residence } \\
\hline Urban & $356(49.2)$ & $1352(60.2)$ & 1 & 1 \\
\hline Rural & $367(49.8)$ & 892(39.8) & $1.69(1.44,2.00)$ & $1.67(1.39,1.99)^{*}$ \\
\hline \multicolumn{5}{|l|}{ Maternal age } \\
\hline $15-19$ & $35(4.8)$ & $170(7.6)$ & $0.61(0.42,0.88)$ & $0.63(0.43,0.93)^{*}$ \\
\hline $20-34$ & $594(82.2)$ & 1834(81.7) & 1 & 1 \\
\hline $35-49$ & 94(13.0) & $240(10.7)$ & $1.27(0.99,1.62)$ & $1.05(0.78,1.41)$ \\
\hline \multicolumn{5}{|l|}{ Gravida } \\
\hline Primigravida & $335(46.3)$ & $1167(52.0)$ & $0.77(0.65,0.92)$ & $0.86(0.71,1.04)$ \\
\hline $2-4$ & 284(39.3) & 839(37.4) & 1 & 1 \\
\hline 5 or more & $104(14.4)$ & 238(10.6) & $1.28(.99,1.66)$ & $0.86(0.64,1.17)$ \\
\hline \multicolumn{5}{|l|}{ Presence of risk factors } \\
\hline Yes & $101(14.0)$ & $140(6.2)$ & $2.49(1.91,3.25)$ & $2.31(1.74,3.07)^{*}$ \\
\hline No & $622(86.0)$ & 2104(93.8) & 1 & 1 \\
\hline \multicolumn{5}{|l|}{ ANC history } \\
\hline Yes & $566(78.3)$ & $1737(77.4)$ & $0.97(0.79,1.18)$ & $0.86(0.67,1.17)$ \\
\hline No or unknown & $157(21.7)$ & $507(22.6)$ & 1 & 1 \\
\hline \multicolumn{5}{|l|}{ HIV status } \\
\hline Yes & $23(3.2)$ & 104(4.6) & $0.76(0.49,1.17)$ & $0.69(0.44,1.08)$ \\
\hline No & 700(96.8) & $2140(95.4)$ & 1 & 1 \\
\hline \multicolumn{5}{|c|}{ Model 2 (proximal factors) } \\
\hline \multicolumn{5}{|l|}{ Abnormal presentation } \\
\hline Yes & $161(22.3)$ & $81(3.6)$ & $7.30(5.51,9.68)$ & $9.80(7.16,13.42)^{*}$ \\
\hline No & $562(77.7)$ & 2163(96.4) & 1 & 1 \\
\hline \multicolumn{5}{|l|}{ Fetal weight $(n=2780)$} \\
\hline$<2500 \mathrm{gm}$ & 84(11.6) & $265(12.9)$ & $1.01(0.78,1.31)$ & $0.85(0.633,1.13)$ \\
\hline 2500-3999 gm & $522(72.2)$ & 1758(85.5) & 1 & 1 \\
\hline $4000 \mathrm{gm}$ and more & $37(5.2)$ & $34(1.6)$ & $3.42(2.13,5.50)$ & $3.93(2.39,6.44)^{*}$ \\
\hline \multicolumn{5}{|l|}{ Previous CS } \\
\hline Yes & 70(79.1) & 19(20.9) & $12.27(7.35,20.49)$ & $13.68(7.87,23.78)^{*}$ \\
\hline No & 653(23.6) & $2225(76.4)$ & 1 & 1 \\
\hline
\end{tabular}

studies [4, 6], corroborated that CS does not confer safety and quality of obstetric care and hence may not prove reduction in maternal and neonatal mortality and morbidity.

Consistent with other studies [2, 13, 21, 26], the most frequent indication of CS observed in our study was obstructed labor. This was mostly due to last moment reporting or transfer of women with obstructed labor to the reference hospital from the periphery. On the other hand, injudicious use of oxytocic drugs or unjustified induction with prostaglandins without prior assessment of risk factors like fetal size, presentation, stage of labor, position and pelvic adequacy might also contribute for the observed over diagnosis of obstructed labor and subsequent emergency CS.

Consistent with a study done southern Ethiopia [20], the second most frequent indication of CS observed in this study was fetal distress. Fetal distress was diagnosed among 115 fetuses. Although using retrospective facility data is often difficult to validate, 84 (73\%) fetuses were 
diagnosed to have non-reassuring fetal heart rate pattern. As none of the fetuses were monitored by continuous electronic fetal monitoring system, over diagnosis of fetal distress is expected. Precise interpretation of fetal heart tracing and use of fetal $\mathrm{PH}$ might be effective in reducing cesarean section rate. Otherwise, inaccurate diagnosis of fetal distress would lead to unjustified use of CS. In general, our findings confirm the need for accurate assessment and better understanding of the mechanism underlying non-reassuring fetal heart rate pattern.

In the current study, mothers who had previous CS were more likely to have CS delivery than their counterparts. Unless there is a clear, compelling and wellsupported justification for CS, a carefully supervised and justified trial of labor is necessary. Trial of scar in singleton pregnancies can be given to reduce rate of repeated cesarean section as the risk of uterine rupture is low [2]. In this study, only one third [27] of the women who had previous CS were allowed to have trial of vaginal delivery and 19 (63.3\%) of them had successful vaginal delivery. This finding is consistent with other researches [27-30].

Consistent with previous studies [26], mothers living in rural area were 1.67 times more susceptible to have current CS delivery than their urban counterparts. This observation may be due to the tendency that rural women are less likely to attend ANC and to get prepared for attending skilled delivery service. Last moment reporting or transfer to the reference hospital is very high in this study. Such challenges in seeking obstetric interventions need to be evaluated in further studies.

Similarly, the chance of undergoing cesarean section would increase as age of the mother increases [31-33]. In this study, women's in age group of 15-19 years were 0.63 times less likely to undertake cesarean section as compared to age group of 20-34 years. The effect of age in this study could be explained by the possibility of pregnancy complication increment by age [25, 34, 35].

Like studies reported in different areas [29,33] mothers reported as having pregnancy risk factors like diabetes and hypertension were at higher odds of undergoing CS delivery in this study. Presence of abnormal presentations, big babies which cause Cephalo pelvic disproportion or malposition, are also consistently reported in other studies $[26,27,33,36]$.

Most of the maternal deaths would have been prevented if general anesthesia was legitimately used. Likewise, the use CS for a dead fetus and the inadequacy of VBAC trial necessitate further explorative study. All of the immediate newborn deaths were reportedly due to respiratory difficulty after birth and which could have been prevented if appropriate and timely care has been provided. Challenges and difficulties are enormous while organizing an operation to save the lives of mothers and neonates in a resource limited setting, including this hospital. This hospital is often overcrowded by referrals from rural districts and majority of patients are either pregnant women with ruptured uterus, obstructed labor and hemorrhage among others. The chronic shortages of anesthetic drugs, inadequate supply of blood for transfusion coupled with acute shortage of trained anesthetist personnel among others are the glaring gaps that demand immediate intervention.

\section{Limitation of the study}

Researches based on secondary data suffer from incompleteness and unreliable information. Use of primary data from the clients would have helped exploring other factors such as obesity, literacy and socioeconomic status. Referral cases might overestimate the true magnitude of Cesarean Section. We did not also assess the quality obstetric care being provided. Therefore, the use of this information for comparison and decision-making should consider the inherent limitation of the study.

\section{Conclusion}

Obstetric factors occurring around birth, including obstructed labor and fetal distress were the main reasons leading to Cesarean Section rather than background characteristics assumed to be a risk. The results imply that there is a need for timely and accurate screening of women during obstetric care and, decision to perform cesarean section should be based on clear, compelling and well-supported justifications. In addition, training of hospital staff, health officers, midwives and health extension workers in emergency obstetric care as well as neonatal resuscitation skills, and use of partograph for appropriate decision to undertake CS are critical. Finally, ensuring access to life saving drugs, supplies, and adequate blood for transfusion are necessary to reverse the current situation. Further research with robust methodology is needed to explore the quality of care being provided and to corroborate or refute the present findings.

\section{Competing interests}

The authors declared that they have no competing interests.

Authors' contribution

$F A, A G, A K$ and $G E$ wrote the proposal and participated in data collection. FA and AG did analysis of the data and write up of the manuscript.

All authors read and approved the final manuscript.

\section{Author details}

${ }^{1}$ Strengthening Human Resource for Health Project, iNGO, P.O. Box, 1566 Bahir Dar, Ethiopia. ${ }^{2}$ Institute of Public Health, University of Gondar, Gondar, Ethiopia. ${ }^{3}$ Maternal and Child Survival Program, iNGO, Addis Ababa, Ethiopia.

Received: 21 July 2015 Accepted: 31 December 2015

Published online: 20 January 2016 


\section{References}

1. National Collaborating Centre for Women's and Children's Health Caesarean section Guidline. Royal College of Obstetricians and Gynaecologists, 27 Sussex Place: RCOG Press; 2004

2. Shamshad B. Factors Leading To Increased Cesarean Section Rate Gomal J Med Sci. 2008:6:1.

3. Panditrao S. Intra-operative difficulties in repeat cesarean sections. J Obstet Gynecol India. 2008;58(6):507-10.

4. World Health Organization. Monitoring emergency obstetric care: a handbook. 2009.

5. Althabe F, Belizán J. Caesarean section: the paradox (comment). Lancet. 2006:368(9546):1472-3.

6. Adnan A, Abu O, Suleiman H, Abu A. Frequency Rate and Indications of Cesarean Sections at Prince Zaid Bin Al Hussein Hospital - Jordan. J Med Sci Clin Res. 2012;19(1):82-6.

7. Lauer JA, Betrán AP, Merialdi M, Wojdyla D. Rates of caesarean section: analysis of global, regional and national estimates. Paediatr Perinata Epidemiol. 2007:28:98-113.

8. Bewley S, Cockbum J. The unethics of 'request' caesarean section. BJOG 2002;109:593-6.

9. Allen VM, O'Connell CM, Baskett TF. Maternal Morbidity Associated With Cesarean Delivery Without Labor Compared With Spontaneous Onset of Labor at Term. Obstet Gynecol. 2003;102:477-82.

10. Francome C, Savage W. Caesarean section in Britain and the United States $12 \%$ or $24 \%$ : is either the right rate? Soc Sci Med. 1993;37:1199-218.

11. Jeremy A, Ana P, Mario M. Determinants of caesarean section rates in developed countries: supply, demand and opportunities for control World Health Report Background Paper. 2010;29

12. Lauer J, Betrán A. Decision aids for women with a previous caesarean section: focusing on women's preferences improves decision making. BMJ. 2007:334:1281-2.

13. Lei $H$, Wen $S$, Walker M. Determinants of caesarean delivery among women hospitalized for childbirth in a remote population in China. J Obstet Gynaecol Can. 2003;25:937-43.

14. Leitch C, Walkers J. Cesarean section rates. BMJ. 1994;308:133-4

15. Lepercq J. Factors associated with cesarean delivery in nulliparous women with type 1 diabetes. Obstet Gynecol. 2010;115(5):1014-20.

16. Lydon-Rochelle M, Holt V, Easterling T, Martin D. Risk of uterine rupture during labour among women with a prior caesarean delivery. N Engl J Med. 2001;345:3-5.

17. Thomas J, Paranjothy S. Royal College of Obstetricians and Gynaecologists: Clinical effectiveness Support Unit. The National Sentinel Caesareans section Audit Report. London: RCOG Press; 2001.

18. Belizán J, Althabe F, Barros F, Alexander S. Rates and implications of caesarean sections in Latin America: ecological study. BMJ. 1999;319:1397-400.

19. Najmi R, Rehan N. Prevalence and determinants of caesarean section in a teaching hospital of Pakistan. J Obstet Gynaecol. 2000;20:479-83.

20. Moges A, Ademe B, Akessa G. Prevalence and Outcome of Caesarean Section in Attat Hospital, Gurage Zone, SNNPR, Ethiopia. Arch Med. 2015;7:4

21. Tsega F, Mengistie B, Dessie Y, Mengesha M. Prevalence of Cesarean Section in Urban Health Facilities and Associated Factors in Eastern Ethiopia: Hospital Based Cross Sectional Study. J Preg Child Health. 2015;2(3).

22. Central Statistical Agency [Ethiopia], ICF International. Ethiopia Demographic and Health Survey 2011. Addis Ababa: Central Statistical Agency and ICF International; 2012

23. Paterson-Brown S. Should doctors perform an elective caesarean section on request? Yes as long as the woman is fully informed. BMJ. 1998;317:462-3.

24. Amu O, Rajendran S, Bolaji I. Should doctors perform an elective caesarean sections on request? Maternal choice should not determine method of delivery. BMJ. 1998:317:463-5.

25. Kenny LC, Lavender T, McNamee R, O'Neill SM, Mills T, Khashan AS. Advanced Maternal Age and Adverse Pregnancy Outcome: Evidence from a Large Contemporary Cohort. PLoS One. 2013;8(2):e56583. doi:10.1371/ journal.pone.0056583.

26. Al-Mulhim A. Factors Affecting the Rate and the Indications of Primary Caesarean Section. Bahrain Med Bul. 2001:23(4):160-2.

27. Stivanello E, Rucci P, Lenzi J, Fantini M. Determinants of cesarean section delivery: a clasification tree analysis. BMC Pregnancy Childbirth. 2014;14(215):1471-2393.
28. Malede B, Yirgu G. Factors associated with success of vaginal birth after one caesarean section (VBAC) at three teaching hospitals in Addis Ababa, Ethiopia. BMC Pregnancy Childbirth. 2013. doi:10.1186/1471-2393-13-31.

29. Karim F, Ghazi A, Ali T, Aslam R, Afreen U, Farhat R. Trends and determinants of ceasarean section. Surgery Pakistan. 2011;16:1.

30. Kassak K, Ali M, Abdallah A. Opting for a cesarea:What determines the decision? Public Admin Managment. 2000;13(3):100-22.

31. Gutema $H$, Shimye A. cesarean section and associated factors at mizan aman general hospital, southwest Ethiopia. J Gynecol Obstet. 2014;2(3):37-41.

32. D'orsi E, Chor D, Giffin K, Angulo-Tuesta A, Barbosa G, Sousa Gama A, et al. Factors associated with cesarean section in public hospial in Rio de Janeiro, Brazil. Artigo Article. 2006;22(10):2067-78.

33. Patel R, Peters T, Murphy D. Prenatal risk factors for Caesarean section. Analyses of the ALSPAC cohort of 12944 women in England. Int J Epidemiol. 2005:34(2):353-67.

34. Greenberg MB, Cheng YW, Sullivan M, Norton ME, Hopkins LM, Caughey AB Does length of labor vary by maternal age? AJOG. 2007;197(4):428. e1-.e7

35. Mary N, Judith U, Hibbard M. Contemporary Labor Patterns and Maternal Age. Obstet Gynecol. 2013;122(5):1018-24.

36. Alrowaily M, Alsalem F, Abolfotouh M. Cesarean section in a high-parity community in Saudi Arabia: clinical indications and obstetric outcomes. BMC Pregnancy Childbirth. 2014;14(92):1471-2393.

\section{Submit your next manuscript to BioMed Central and we will help you at every step:}

- We accept pre-submission inquiries

- Our selector tool helps you to find the most relevant journal

- We provide round the clock customer support

- Convenient online submission

- Thorough peer review

- Inclusion in PubMed and all major indexing services

- Maximum visibility for your research

Submit your manuscript at www.biomedcentral.com/submit

) Biomed Central 